\title{
Assessment of soil radon potential in Hong Kong, China, using a 10-point evaluation system
}

\author{
S. Tung $\cdot$ J. K. C. Leung $\cdot$ J. J. Jiao $\cdot$ \\ J. Wiegand $\cdot$ W. Wartenberg
}

Received: 7 January 2011 / Accepted: 5 June 2012/Published online: 29 June 2012

(C) The Author(s) 2012. This article is published with open access at Springerlink.com

\begin{abstract}
Radon and its progenies have been ranked second of being responsible for lung cancer in humans. Hong Kong has four major groups of uranium-rich plutonic and volcanic rocks and is suffering from radon emanated therefrom. However, there is a lack of radon potential maps in Hong Kong to resolve the spatial distribution of radonprone areas. A ten-point radon potential system was
\end{abstract}

Electronic supplementary material The online version of this article (doi:10.1007/s12665-012-1782-0) contains supplementary material, which is available to authorized users.

\section{S. Tung $(\square)$}

Department of Physics, The University of Hong Kong,

Room 419, Chong Yuet Ming Physics Buliding, Pokfulam Road,

Hong Kong, China

e-mail: STUNGJ@gmail.com; jaytung@hku.hk

\section{J. K. C. Leung}

Department of Physics, The University of Hong Kong,

Room 420, CYM Physics Building, Pokfulam Road, Hong Kong, China

e-mail: jkcleung@hku.hk

\section{J. J. Jiao}

Department of Earth Science, The University of Hong Kong, Room 302, James Lee Building, Pokfulam Road, Hong Kong, China

e-mail: jjiao@hku.hk

\section{J. Wiegand}

DMT GmbH \& Co. KG Exploration \& Geosurvey Division/

Geology and Borehole Survey, Am Technologiepark 1,

45307 Essen, Germany

e-mail: Jens.Wiegand@dmt.de

\section{W. Wartenberg}

Department of Geoecology, Institute for Chemistry and Biology of the Marine Environment, University of Oldenburg, Room 1. OG 115, Schleusenstr. 1, 26382 Wilhelmshaven, Germany e-mail: wolfam.wartenberg@terramare.de developed in Germany (2005) to predict radon potential using both the in situ geogenic and geographic parameters under hierarchical ranking. Primarily, the ten-point system requires the desk study of the geological environment of sampling sites, which has an advantage of saving resources and manpower in extensive radon potential mapping over the traditional soil radon concentration sampling method. This paper presents a trial of radon potential mapping in Hong Kong to further verify the system. Despite some slight departures, the system demonstrates an acceptable correlation with soil radon concentrations $\left(R^{2}=0.62-0.66\right)$ from 768 samples of mainly intermediate radon potential. Hong Kong has a mean soil radon concentrations of $58.9 \mathrm{kBqm}^{-3}$, while the radon potential from the ten-point system achieves an average of 4.93 out of 10 over the territory. The vicinity of fault zone showed high soil radon concentrations and potentials, which were conducive to uranium enrichment and rapid soil-gas diffusion near faults. High uranium-238 content in soil was found to cause high soil radon concentration with a large $R^{2}, 0.84$. The Jurassic granite and volcanic crystal tuff cover more than $85 \%$ of the whole Hong Kong area, and they show relatively high radon concentrations (Geometric mean 83 and $49 \mathrm{kBqm}^{-3}$, respectively) which are associated with their high uranium contents (Geometric mean 234 and $197 \mathrm{Bqkg}^{-1}$, respectively). While indoor radon concentration is an important factor for radon risk assessment, this study has not considered the correlation between indoor radon concentration and radon potential. The reason is that almost all buildings in Hong Kong are high-rise buildings where indoor radon concentrations are governed only by the radium content in the building materials and the ventilation conditions.

Keywords Radon potential - Radon concentration · Faults $\cdot$ Ten-point system $\cdot$ Hong Kong 


\section{Introduction}

\section{Development of radon potential}

Radon, in its metastable form, is the most abundant radioactive gas in nature, to which human beings are mostly exposed. Radon and its progenies are together ranked as the second highest cause of lung cancer mortality (Darby et al. 2001). Indoor radon concentrations are usually higher than atmospheric radon concentration by a factor of 10 in most countries and account for more than $50 \%$ of total human exposure from natural radioactive sources (UNSCEAR 1994; Harley et al. 1988).

The relation between radionuclides in building materials and indoor ventilation conditions and the indoor radon concentration is revealed in different extents for high-rise buildings (Yu et al. 1996; Leung et al. 1998). On the contrary, the soil-gas radon concentration, which generally ranges from several thousand or hundred thousand $\mathrm{Bqm}^{-3}$, is proposed to be the major source of indoor radon for lowrise buildings (Kemski et al. 2001). The linkage between soil-gas and indoor radon concentration has been studied heavily in the past decades, including a number of analytical and numerical radon entry models developed to predict the indoor radon level from radon-bearing soil gas (Gadgil 1992). Substantial works on, for example, radon potential and radon index have been undertaken on identifying soil-radon prone sites before applying any radon entry models (Barnet et al. 2008; Kemski et al. 2009; Wiegand 2001). Therefore, the development of a good geogenic radon potential system is highly valued as long as the regional assessment of radon risk is demanded.

Kemski et al. (1996) suggested a radon ranking matrix by taking soil radon concentration and soil permeability into account of radon potential. This system, however, is highly affected by meteorological factors, particularly the variation of soil moisture conditions. USGS (1995) developed another system by accounting indoor radon, aerial radioactivity, geology, architecture type and soil permeability into radon potential. The system cannot provide any estimates when no houses are available in inspected areas. Collectively, the aforementioned two systems do not take the meteorological influence on soil permeability into account and hence may involve uncertainties. For instance, the soil-gas radon concentration can vary inversely with the soil permeability. Currently, most of the developed radon potential systems are thus based on soil-gas radon concentration and soil permeability as key parameters (Kemski et al. 2001; Reimer 1992; Buttafuoco et al. 2007). The accuracy of modern radon potential maps would be improved but with limitation on extent of mapping on the ground that experimental work involved in estimating these parameters often requires a higher degree of knowledge and resources.
A 10-point radon potential system

Wiegand (2001) proposed a 10-point radon potential system, which requires no measurement of soil radon concentration and permeability. On the contrary, the system involves the inspection of in situ geogenic and anthropogenic factors such as geology, relief, vegetation cover, tectonics, soil sealing and traffic vibrations (Table 1). The system enables radon potential more conveniently to be assessed in anywhere once geological maps are available. Those parameters can be studied on desk and the radon potential can be estimated over a large area. Extensive mapping of radon potential across countries or even continents is facilitated under this system, which provides a prominent common ground for scientists to study radon potential (Wiegand 2005).

In Table 1, the origin of soil is assessed and represented by either " 0 " or " 2 " as a part of overall potential score $(\leq 10)$. The underlying rocks play a critical role in radon potential within natural soil. The rocks of higher uranium content, e.g. shale, granite and crystal tuff carry points as high as "3" whereas those low-uranium sandstones, conglomerate and basalt carry " 0 ". When the soil backfill is $>2 \mathrm{~m}$, a higher probability of incorporated human disturbance is expected and the type of backfill then becomes a key of radon potential. High-uranium backfills such as slag and ashes weigh 2 points while low-uranium sand and gravel carry zero point. On the one hand, the parameter "relief" accounts for the effect of the distribution of grain size caused by erosion as well as soil development and the impact of soil permeability along slopes on radon potential. The upper part of the hill favorable to radon emanation carries "1" point (Wiegand 2001). On the other hand, heavy vegetation carries " 0 " due to the exhaustion of soil radon through transpiration, reduced soil moisture and increased soil permeability (Lewis and MacDonell 1990). Last but not least, the parameter "faults" is one of the major concerns in the local parameters. It carries " 1 " point as the possibly high soil moisture and vast uranium deposition near faults are in favor of radon emanation (Choubey et al. 2000; Kemski et al. 1992; Wiegand 2001). As long as only the soil radon in rural/natural areas is concerned, the effect of traffic vibration and soil sealing are not considered in this study.

Wiegand (2005) presented figures of soil radon potential and concentration mainly from Quaternary to Cretaceous materials in Germany from which there shows a strong correlations $\left(R^{2}=0.94-0.99\right)$ between 10 -point radon potential and the soil radon concentration (Bleile et al. 2005). In this study, the potential system was further verified in Hong Kong using the same instrumentation adopted by Wiegand. Hong Kong provides a reasonably desirable ground for further testing the versatility of 10-point system 
Table 1 A ten-point radon potential system (Wiegand 2001)

\begin{tabular}{|c|c|}
\hline Parameter & Classic RP \\
\hline \multicolumn{2}{|l|}{ Origin of soil } \\
\hline (1) undisturbed soil or backfill $<2$ m (go to 2.1 ) & 2 \\
\hline (2) backfill > 2 (go to 2.2 ) & 0 \\
\hline \multicolumn{2}{|l|}{ 2. Geology } \\
\hline \multicolumn{2}{|l|}{2.1 Variety of rocks } \\
\hline Sediment: black shale, phosphorite, bauxite & 3 \\
\hline \multicolumn{2}{|l|}{$\begin{array}{l}\text { Magmatic rock: (a) silicic rocks (e.g. granite, granodiorite, syenite, monzonite, } \\
\text { Rhyolite, rhyolite lava, dacite, pumice, pegmatite), (b) Alkaline rocks (e.g. phonolite, nephelinite) }\end{array}$} \\
\hline \multicolumn{2}{|l|}{ Volcanic rock: crystal tuff } \\
\hline \multicolumn{2}{|l|}{ Metamorphic rock: orthogneiss, greisen } \\
\hline $\begin{array}{l}\text { Sediment: gravel, clay, pelite, carbonate rock, loess, mudstone, Metasiltsone, metaconglomerate, } \\
\text { metasandstone, eutaxite }\end{array}$ & 1 \\
\hline \multicolumn{2}{|l|}{ Magmatic rock: intermediate rocks (e.g. diorite, andesite) } \\
\hline \multicolumn{2}{|l|}{ Volcanic rock: trachyte, tuff, tuffite } \\
\hline \multicolumn{2}{|l|}{ Metamorphic rock: clay schist, mica schist, paragneiss, granulite, marble } \\
\hline Sediment: sand, sandstone, conglomerate, evaporite, silstone, silicified sandstone & 0 \\
\hline \multicolumn{2}{|l|}{ Magmatic rock: (a) mafic rocks (e.g. gabbro, basalt, diabase) (b) ultramafic rocks (e.g. peridotite) } \\
\hline \multicolumn{2}{|l|}{ Metamorphic rock: quartzite, amphibolite, eclogite, serpentinite, metasediments } \\
\hline \multicolumn{2}{|l|}{ 2.2 Type of back fill } \\
\hline High $^{226}$ Ra conc.: slags, ashes, sewage sludge, tailings (ore mining) & 3 \\
\hline Low $^{226} \mathrm{Ra}$ conc.: sand, gravel, soil aggradation, rubble, tailings(coal mining) & 0 \\
\hline \multicolumn{2}{|l|}{ 3. Relief } \\
\hline Upper part of hill & 1 \\
\hline Lower part of hill & 0 \\
\hline Plain & 0 \\
\hline \multicolumn{2}{|l|}{ 4. Vegetation } \\
\hline Grass, field, meadow or no vegetation & 1 \\
\hline Forest, bush, scrub, mixed plantation & 0 \\
\hline \multicolumn{2}{|l|}{ 5. Local parameters } \\
\hline Tectonic elements: fault, mining subsidence & 1 \\
\hline Soil sealing $>50 \%$ e.g. urban area & 1 \\
\hline Strong traffic vibration (trains or trucks) $<10 \mathrm{~m}$ distance & 1 \\
\hline Maximum points & 10 \\
\hline
\end{tabular}

particularly in igneous formations, as the lithology and geomorphology in Hong Kong (>85\% of land being igneous) are significantly different from those in Germany,

\section{Geology of Hong Kong}

Hong Kong is located at the southeastern part of China which is composed of two major tectonic crustal blocks, namely, the Yangtze Block and the Cathaysia Block (Davis et al. 1997; Wiegand 2005). Lying on the southeastern part of the Cathaysia Block, Hong Kong is an endpoint of a north-east trending fault zone, Lianhuashan Fault Zone coupling with a north-east trending belt, Southeast Maritime Fold Belt (Fig. 1, ESM only) (Huang 1980). The former fault zone is about $30 \mathrm{~km}$ wide and extents for several hundred kilometers from Hong Kong to Shanghai (Chen 1987). The fault zone cuts over Hong Kong by intensive sub-parallel north-east and north-west strike-slip faults. Lithologically, more than $85 \%$ of Hong Kong land area is covered by Jurassic and Cretaceous granite and volcanic tuff with various grain sizes. Moderate to high uranium concentrations $(>7.6 \mathrm{ppm})$ were found in most granite and volcanic tuff (Sewell 1999) which makes Hong Kong a very good trial site of 10 -point radon potential mapping on igneous rocks. 


\section{Methodology}

The assessment of radon potential in Hong Kong is jointly studied with the measurement of soil radon concentration and soil uranium content. Field observations for radon potential and soil-gas sampling were done together on 768 localities, in which 63 of these sites were sampled with soil for uranium content.

\section{Sampling strategy}

The sites for assessing soil radon concentration and radon potential were selected randomly over Hong Kong basing on three principles (Fig. 1). First, every geological unit in Hong Kong has to be measured and the fraction of samples taken in each rock type was roughly equal to the proportion of that rock type area over the whole Hong Kong territory. For instance, the number of measurement in volcanic rocks is proportional to its area over whole Hong Kong territory (Table 1, ESM only). Second, the sites should not be located in the areas having heavy artificial disturbance. Any such disturbances were observed through inspecting the landform, the presence of foreign backfill and human constructions. For instance, measurements in urban areas were usually severely influenced by artificial constructions such as cut-slope, bridges, roads, buildings and houses. The migration path of soil gas could be hence highly distorted near those constructions of low permeability. For rural areas, similar problems were found near those areas contaminated by illegally disposed construction wastes. The unknown amount of radionuclides modified by human factors can affect soil radon concentrations up to a factor of 10. Geographically, most of the areas in Hong Kong are rural areas including arable land and country parks, etc.. whereas urban areas and population are both concentrated in northern Hong Kong Island, Kowloon and portions of New Territories (Fig. 2, ESM only). The extraordinarily high population density in urban areas often involves a very high degree of traffics and soil sealing. Measurements were carefully avoided in these built-up areas but concentrated in those rural areas and thus the effect of traffic vibration and soil sealing on radon concentration and potential could be ignored.

Finally, accessibility is another important factor of sampling sites which were chosen to be accessible either by car or on foot. Field trips lasting for more than 1 day were avoided as the soil gas samples had to be returned to the laboratory for measurement every day to preserve the accuracy. The sampling sites were chosen under the aforementioned three principles, and the soil radon concentration and radon potential are examined in their corresponding geological units. With the consideration of avoiding human disturbance and inaccessibility, the result will be more relevant to those natural and accessible areas in each geological unit.

There are totally 768 sites investigated with soil radon concentration and radon potential, including $86 \%$ of the sites on igneous formations with the rest lying on sedimentary formations and superficial deposits. Concerning the regional tectonics, Hong Kong is located within the Lianhuashan fault zone, which is a dominant member of the tectonic setting in Southern China. The fault zone is primarily composed of northwestern and northeastern strike-slip faults. About $27 \%$ of the sites were located near faults to reveal any possible anomalies.

\section{Sampling plan}

The whole sampling period lasted for about 22 months which was divided into two phases (Table 2, ESM only and Fig. 3, ESM only). In phase 1, about 1 year was spent to measure 189 samples randomly collected over 25 geological units. The purpose of phase 1 was twofold. First, the measurements were aimed to cover all significant geological units to gain an overall picture of soil radon concentration and potential in Hong Kong. Second, measurements were designed to explore radon concentrations near faults and prepare for further analyses along faults in phase 2 .

In phase 2, about 579 sites were visited in another year. Among these 579 sites, 100 sites were near the sampling regions in phase 1 with the rest 479 sites taken in other regions. From experience of phase 1, granite and tuff units are more likely to be highly radon-concentrated regions compared with other geological units. Furthermore, faults and relief are expected to be significant factors contributing to the abundance of radon in soil. Collectively, the sampling sites in phase 2 were selected for the purposes of (1) re-sampling the sites of phase 1 in greater details, (2) exploring and sampling more areas over granite and tuff, (3) having more samples near the faults and (4) extending the size of sampling area over the whole Hong Kong territory.

Soil gas sampling for radon concentration

The soil gas sampling was undertaken with a small-diameter hollow steel probe with a free, sharp lower end (a lost tip) combined with a large-volume syringe $(150 \mathrm{~mL})$. A Lucas cell was flushed by $300 \mathrm{~mL}$ of soil gas and then sealed for laboratory measurement. The samples were then kept for at least $3 \mathrm{~h}$ before measurement to allow the establishment of a transient equilibrium between radon and its progenies.

The entire sampling system was perfectly sealed to avoid contamination by atmospheric air. The soil gas samples were retrieved from an average depth of $0.9 \mathrm{~m}$ to 


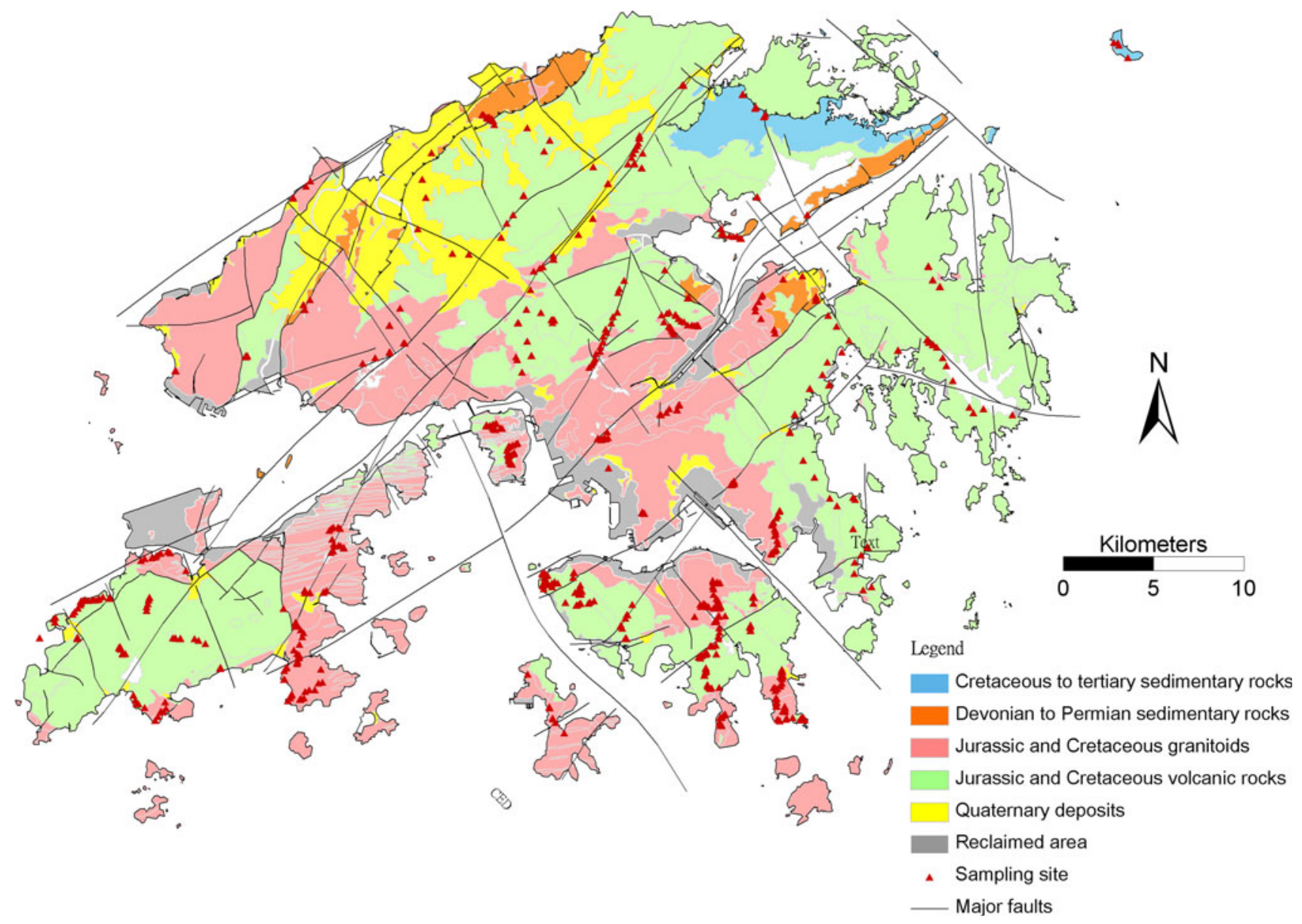

Fig. 1 The geological map of Hong Kong and the sampling sites

reduce contamination. The cavity created at the lower end of the sampling probe enabled a satisfactory environment for gas-sample collection. The soil gas samples were measured in laboratory by a photomultiplier-tube-based radon detector for radon concentration.

\section{0-point Radon potential ranking}

Under the scheme of the 10-point radon potential system, each site is ranked with a radon potential. The potential is derived from five controlling parameters, namely, the origin of soil, geology, relief, vegetation and tectonic elements. The system declares a numerical radon potential to each site by assigning appropriate scores according to these parameters (Table 1) (Wiegand 2005).

\section{Soil sampling for soil uranium content}

The decay of soil uranium-238 produces numerous decay products including soil radon-222. The distribution of radon concentration in soil gas is thus considered to be related with that of uranium-238 in soil (Barnet et al. 2008). Therefore, 63 sites were selected and sampled with soil for uranium content analysis (Fig. 2). The soil samples were taken from a depth of $5 \mathrm{~cm}$ and stored in a polyethylene bag. To remove unwanted moisture, the samples were then dried in an oven at $200{ }^{\circ} \mathrm{C}$ for at least $24 \mathrm{~h}$ and the dry mass of each sample was controlled to be about $500 \mathrm{~g}$ in weight. A high-purity germanium gamma ray spectroscopy system was used to measure the concentration of uranium-238 and other radionuclides in these soil samples.

\section{Results}

Radon potential map in Hong Kong

The 10-point system ranks radon potential points $0-3$, points $4-6$ and points $7-10$ as low, medium and high radon potential, respectively. In Figs. 4 and 5 (ESM only), more than two-thirds of the area in Hong Kong is ranked as 


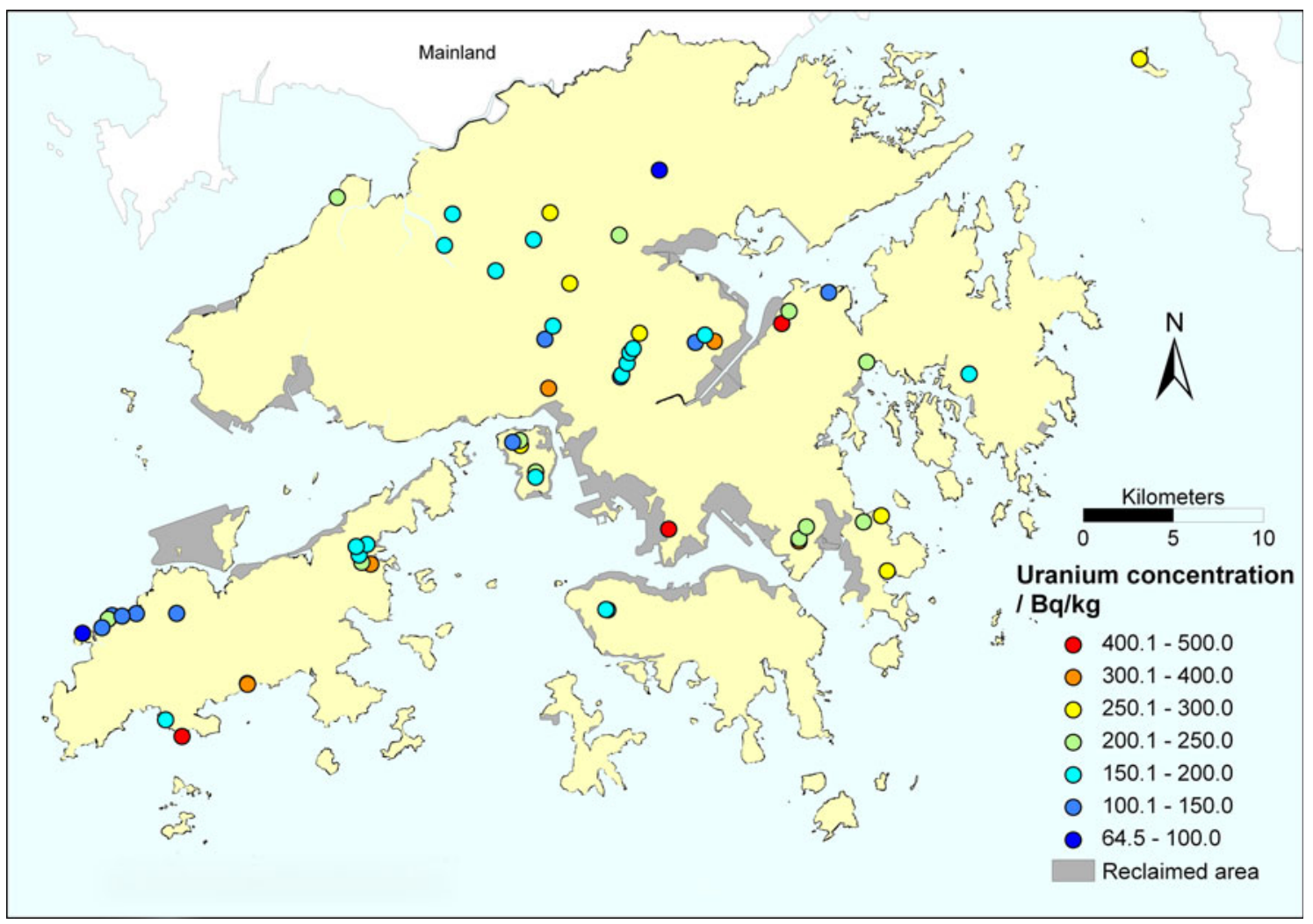

Fig. 2 Uranium concentration of soil samples in Hong Kong

medium radon potential. The low-potential areas including northwestern New Territories account for about $18 \%$ (normalized by area) of the total land, whereas the highpotential areas especially in southwest New Territories and northern Hong Kong Island account for $14 \%$ of the total land. The sites over intrusive and volcanic rocks carry the highest radon potential, while those over superficial deposits carry the least (Table 2). Collectively, the normalized geometric mean of radon potential in Hong Kong was about 4.93 , falling into medium radon potential.

\section{Radon concentration map in hong kong}

The soil radon concentration $[\mathrm{Rn}]$ is defined as low for $[\mathrm{Rn}]<10 \mathrm{kBqm}^{-3}$, medium for $10<[\mathrm{Rn}]<100 \mathrm{kBqm}^{-3}$ and high for $[\mathrm{Rn}]>100 \mathrm{kBqm}^{-3}$. As shown in Figs. 6 and 7 (ESM only), about $60 \%$ of the areas correspond to medium soil radon concentration. Low-radon-concentration areas particularly in northwestern New Territories account for about $6 \%$ of the total land. In contrast, those high-radonconcentration areas like southwest New Territories and northern Hong Kong Island accounting for $32 \%$ of the total land. Macroscopically, the normalized geometric mean of the radon concentration for the whole territory is $58.9 \mathrm{kBqm}^{-3}$, which falls into medium radon concentration. Amongst numerous lithological units, the radon concentration over intrusive rocks is the highest with a geometric mean of $82.7 \mathrm{kBqm}^{-3}$ followed by that of volcanic rocks of $49.1 \mathrm{kBqm}^{-3}$ (Table 3 ). The radon concentration analysis also suggests that eutaxite and fine-tomedium-grained granite show the highest radon concentrations among intrusive rocks and volcanic rocks, respectively (Fig. 8, ESM only). The radon concentrations of four volcanic groups, namely, Kau Sai Chau, Repulse Bay, Lantau and Tsuen Wan range from about 30 to $50 \mathrm{kBqm}^{-3}$ (Table 4), while those of four plutonic suites, namely,

Table 2 Ten-point radon potential of each lithology with intrusive rocks the highest and superficial deposits the lowest

\begin{tabular}{lllll}
\hline & Intrusive rocks & Volcanic rocks & Superficial deposits & Sedimentary rocks \\
\hline Geometric mean of radon potential & 5.88 & 4.87 & 2.48 & 3.04 \\
Mode of radon potential & 6 & 5 & 2 & 3 \\
Arithmetic standard deviation & 0.82 & 1.28 & 0.94 & 0.94 \\
\hline
\end{tabular}


Table 3 Soil radon concentration of each lithology with intrusive rocks the highest

\begin{tabular}{lllll}
\hline & $\begin{array}{l}\text { Intrusive } \\
\text { rocks }\end{array}$ & $\begin{array}{l}\text { Volcanic } \\
\text { rocks }\end{array}$ & $\begin{array}{l}\text { Sedimentary } \\
\text { rocks }\end{array}$ & $\begin{array}{l}\text { Superficial } \\
\text { deposits }\end{array}$ \\
\hline $\begin{array}{l}\text { Geometric mean of uranium } \\
\text { concentration }\left(\mathrm{Bqkgm}^{-3}\right)\end{array}$ & $\begin{array}{l}82.65 \\
(+145.94,-52.77)\end{array}$ & $\begin{array}{c}49.10 \\
(+101.12,-33.05)\end{array}$ & $\begin{array}{c}35.36 \\
(+41.17,-19.02)\end{array}$ & $\begin{array}{c}37.98 \\
(+123.56,-29.05)\end{array}$ \\
\begin{tabular}{l} 
No. of sampled site \\
\hline
\end{tabular} & 334 & 325 & 58 & 51 \\
\hline
\end{tabular}

Table 4 Soil radon concentration of each volcanic group with Tsuen Wan group the highest

\begin{tabular}{llllr}
\hline Volcanic group & Kau Sai Chau volcanic & $\begin{array}{l}\text { Repulse Bay volcanic } \\
\text { group }\end{array}$ & $\begin{array}{l}\text { Lantau volcanic } \\
\text { group }\end{array}$ & $\begin{array}{l}\text { Tsuen Wan volcanic } \\
\text { group }\end{array}$ \\
\hline Geometric mean of radon & 36.07 & 48.54 & 29.51 & 61.14 \\
concentration $\left(\mathrm{kBqm}^{-3}\right)$ & $(+44.19,-19.86)$ & $(+90.61,-31.61)$ & $(+85.01,-21.90)$ & $(+109.77,-39.27)$ \\
Number of sample & 21 & 146 & 34 & 135 \\
\hline
\end{tabular}

Table 5 Soil radon concentration of each suite with Cheung Chanu Suite the highest

\begin{tabular}{llllr}
\hline Granitic suite & Lion Rock Suite & Cheung Chau Suite & Kwai Chung Suite & Lamma Suite \\
\hline Geometric mean of radon & 87.62 & 99.50 & 75.44 & 84.32 \\
concentration $\left(\mathrm{kBqm}^{-3}\right)$ & $(+136.57,-53.37)$ & $(+186.51,-64.89)$ & $(+122.73,-46.72)$ & $(+156.26,-55.13)$ \\
Number of sample & 21 & 16 & 34 & 135 \\
\hline
\end{tabular}

Table 6 Soil radon concentration of each lithology with intrusive rocks the highest

\begin{tabular}{llllr}
\hline & Intrusive rocks & Volcanic rocks & Sedimentary rocks & Superficial deposits \\
\hline Geometric mean of uranium & 234.29 & 197.19 & 126.63 & 187.55 \\
concentration $\left(\right.$ Bqkgm $\left.^{-3}\right)$ & $(+413.70,-149.58)$ & $(+83.95,58.88)$ & $(+78.67,-48.52)$ & $(+16.29,14.99)$ \\
No. of sampled site & 31 & 19 & 8 & 5 \\
\hline
\end{tabular}

Lion Rock, Cheung Chau, Kwai Chung, Lamma range from 75 to $100 \mathrm{kBqm}^{-3}$ (Table 5).

Soil uranium analysis in selected sites

The average uranium content of each lithology in Hong Kong ranges from 127 to $234 \mathrm{Bqkg}^{-1}$ (Table 6). Soil samples in northern New Territories and northern Lantau Island show lower uranium concentrations $\left(<200 \mathrm{Bqkg}^{-1}\right)$ than those in Kowloon ranging from 200 to $500 \mathrm{Bqkg}^{-1}$ (Fig. 2). Soil samples over granitic rocks demonstrate the highest uranium concentration $\left(234 \mathrm{Bqkg}^{-1}\right)$, followed by those over volcanic rocks (197 $\mathrm{Bqkg}^{-1}$ ) (Table 6). This result is in accordance with the theory that felsic rocks, e.g. granite, usually have higher concentrations of uranium than mafic rocks with reference to the process of crystallization (Brookins 1990). The concentrations of uranium in superficial deposits $\left(188 \mathrm{Bqkg}^{-1}\right)$ are slightly lower than that of igneous rocks, whereas those of Mesozoic pre-volcanic sedimentary rocks are the lowest.

\section{Discussion}

Radon potential and radon concentration

The sites of low radon potential are more probable to show lower radon concentrations than those sites of the medium and high radon potential (Fig. 10, ESM only and Fig. 11, ESM only). It is also evident that the radon concentration distributions in medium and high radon potential group are generally similar (Fig. 11, ESM only), while mediumradon-potential sites attain radon concentrations which are averagely $25 \%$ of those with high radon potential (Fig. 10, ESM only). Lithologically, a general consistence could be observed between the radon potential and radon concentrations. For instance, the most radon-prone areas (Table 2), namely, granitic areas attain a soil radon concentration of $82.7 \mathrm{kBqm}^{-3}$, which is $40 \%$ higher than the overall average $58.9 \mathrm{kBqm}^{-3}$ over all geological units (Table 3). To further illustrate the correlation between soil radon concentration and radon potential, the average radon 


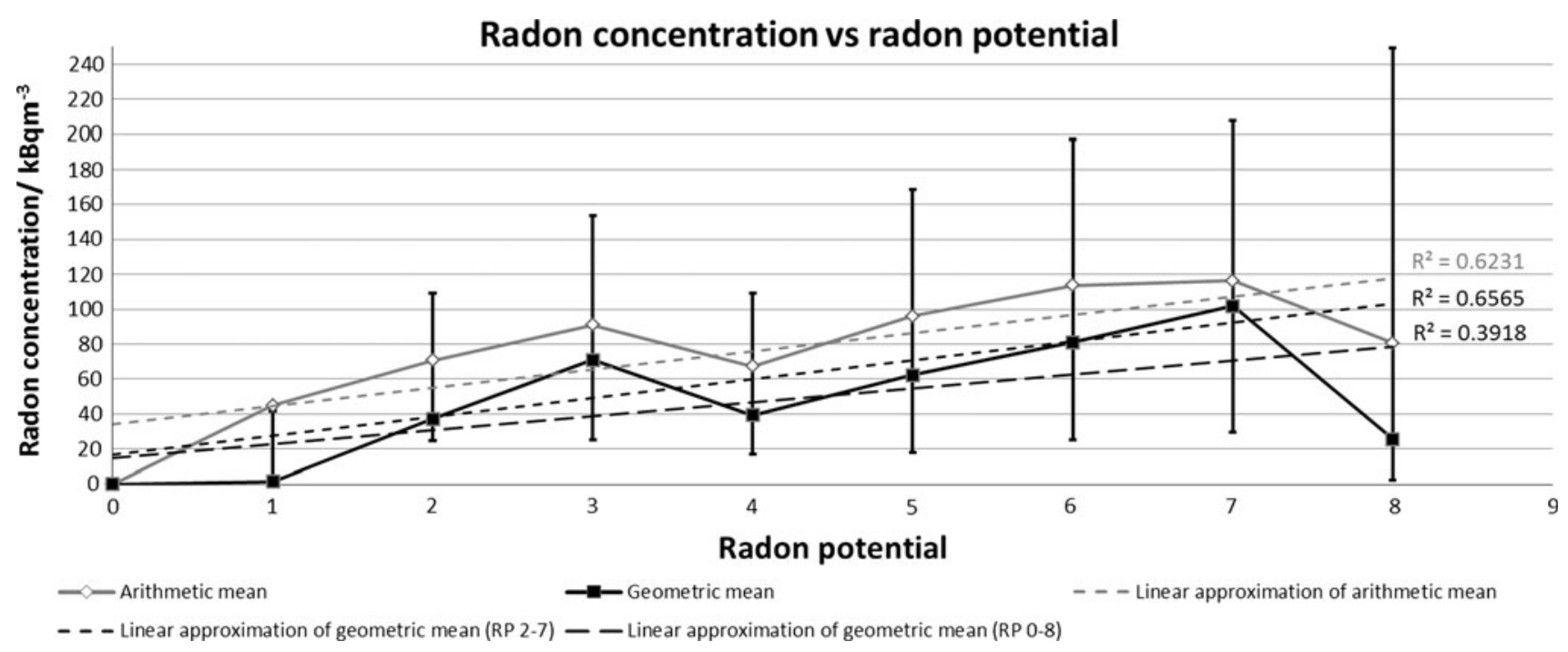

Fig. 3 Linear regression between soil radon concentration and 10-point radon potential. Error bars are the geometric standard deviations with respect to geometric mean

concentration in each radon potential group are plotted against the radon potential (Fig. 3). The analysis takes advantage of both arithmetic and geometric mean to acquire a representative radon concentration in each radon potential rank. The involved geometric mean of soil radon concentration is obtained by normal distribution approximation (Fig. 9, ESM only and Table 7). The radon concentration distributions follow nicely with normal distributions except for small sample number cases, for example, potential of 2, 3, 4 (Fig. 9, ESM only). However, in these cases, even though the fitted normal distributions are questionable, the means do not seem to deviate much from the expected values.

Macroscopically, the linear regressions of $R^{2}$ values ranging from 0.39 to 0.66 indicate a particularly strong correlation between radon concentration and intermediate radon potential of $2-7$ while high radon potential $(\sim 8)$ does not promise a soil radon concentration (Fig. 3). The correlation between arithmetic mean of soil radon concentration and 10-point radon potential is as good as $R^{2}=0.62$ (Fig. 3). However, the correlation deviates considerably $\left(R^{2}=0.39\right)$ for geometric mean of soil radon concentration and the corresponding radon potential. Those points of radon potential 0,1 and 8 , which fall apart from the positive trend, possibly explain this low correlation (Fig. 3). Technically, the falling apart could be the result of small sample size $(<30)$ within the corresponding radon potential (Table 7). However, a good positive correlation $\left(R^{2}=0.66\right)$ between geometric mean of soil radon concentration and radon potential is achieved when regressing in the range of radon potential from 2 to 7 , implying that the 10-point system works quite well in intermediate radon potentials in Hong Kong. Regarding the geometric mean of potential from 2 to 7 (Fig. 3), a quite clear linear trend is observed in potential from 4 to 7 . However, the sites of radon potential 2 and 3 show higher radon concentrations than those extrapolated by the trend. Most sites ranked with potential 2 or 3 were the areas over sediments (e.g. sand and silts) which contributed " 0 " point to the radon potential, referring to Table 1 . To explain the unexpected high radon concentrations, it was highly probable that some high-uranium sediments from the nearby high-uranium rocks were transported to the areas in form of debris flow. The large standard deviation of potential 8 (mostly near fault) also echoes with its outlying radon concentrations (Fig. 3) and thus reflects a diverse environment near faults.

Radon concentration and uranium

The geological units in Hong Kong are defined by the rock type (Volcanic rocks, granitoids or intrusive rocks, sedimentary rocks and quaternary deposits) and the formation time (Sewell et al. 2000). The former two igneous rock types, which inherit highest uranium content, contribute to the highest soil radon concentration (Fig. 4). The data point of superficial deposits falls apart from linear relation (Fig. 4). Its medium uranium concentration of about $40 \mathrm{Bqkg}^{-1}$ is probably the result of diluting effect of mixing high-uranium component, e.g. clay and low-uranium components, e.g. clay. Its radon concentration (close to the mean of volcanic rocks) can be inferred by the similar argument.

\section{Granite suites and Volcanic groups}

The four pairs of volcanic group and granitic suite in Hong Kong are categorized basing on their time of formation (Table 3, ESM only) and their radon concentration 
distributions are shown (Table 4 and Table 5). The first three suite-group pairs show a pretty good conformity of radon concentrations between suites and groups (Fig. 5). Tsuen Wan volcanic group, which is mainly fine to coarse ash crystal tuff, demonstrates the highest radon concentration of $61.1 \mathrm{kBqm}^{-3}$ among volcanic groups (Table 4), while Cheung Chau suite, which is mainly fine to medium grained granite, shows the highest radon concentration of $99.5 \mathrm{kBqm}^{-3}$ among suites (Table 5).

Contribution of faults to radon concentration in Hong Kong

The soil radon concentrations were found to be higher in the vicinity of faults or fracture zones (Table 8). Radon anomalies observed near faults were generally due to the extra deposition of uranium from underground water (Al-Tamimi and Abumurad 2001; Hagmaier 1972) and additional transportation of radon along the facture zones (Kristiansson and Malmqvist 1982). The soil radon concentrations over granite $50 \mathrm{~m}$ within and outside of faults were quite similar due to two reasons (Fig. 12, ESM only). First, the unloading joints in granite encourage extra level of fracture near faults with width up to $1 \mathrm{~km}$ (Sewell et al. 2000) and thus enlarge the areas of anomaly. Second, granite is generally less resistant to weathering than other igneous rocks and typically has larger fracture zones (Fufe et al. 2000).

Uncertainties and limitations of the study

The quality of in situ investigation and geological understanding controls the accuracy and precision of the estimated radon potential. However, all factors concerned in 10-point system are not subjected to any immediate meteorological changes. Therefore, the reliability of 10-point system is guaranteed as long as the estimated radon potentials are highly reproducible and favorable for comparison. Lithological boundaries were adopted in the maps of radon potential and concentration under an argument that the lithology possesses a strong linkage with those parameters in the 10-point system. The geometric mean of every measuring parameter was adopted to represent for each lithological unit. As measurements were taken from mostly the accessible (near footpaths and roads) and natural areas, a great caution has to be exercised when assessing the radon potential in any inaccessible/remote and human disturbed areas through the maps.

Indoor radon concentration and radon potential

Hong Kong is a densely populated city where most people live in high-rise buildings. Hence indoor radon 
Fig. 4 Linear dependence between soil uranium concentration and soil radon concentration $\left(R^{2}=0.8375\right)$ of intrusive rocks, volcanic rocks and sedimentary rocks
Fig. 5 Linear relationship of soil radon concentration between granitic suite and volcanic group with an outlier, pair of Lamma Suite and Tsuen Wan volcanic group. Volcanicsuite pair I, II, III and IV are referring to the Kau-Sai-Chaugroup-Lion-Rock-suite pair, Repulse-Bay-group-CheungChau-suite pair, Lantau-groupKwai-Chung-suite pair and Tsuen-Wan-group-Lamma-suite pair, respectively (Please refer to Table 3, ESM only)

\section{Uranium content vs radon concentration}
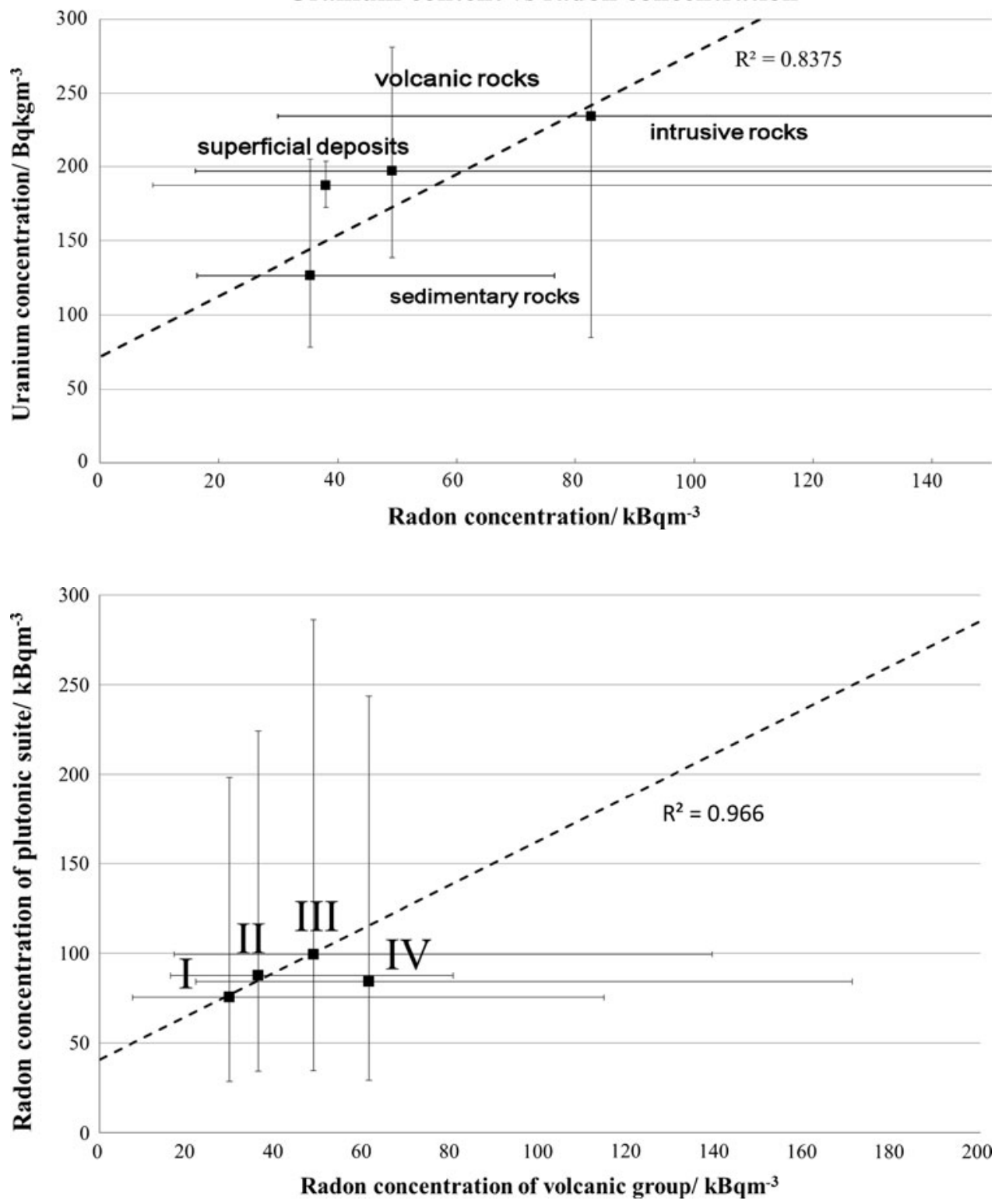

Table 8 Soil gas radon concentration versus distance from detected fault/fault zone

Soil gas radon concentration $\left(\mathrm{kBqm}^{-3}\right)$ and distance from detected faults

\begin{tabular}{llll}
\hline Distance from faults & $<50 \mathrm{~m}$ & $50-100 \mathrm{~m}$ & $>100 \mathrm{~m}$ \\
Geom. mean & 115.6 & 105.7 & 87.5 \\
Arith. mean & 63.8 & 66.2 & 53.1 \\
Median & 71.3 & 65.6 & 66.1 \\
Minimum & 3.5 & 4.6 & 1.8 \\
Maximum & $1,201.3$ & 452.6 & 295.3 \\
\hline
\end{tabular}

concentrations in Hong Kong are mainly governed by the radionuclide contents in building materials and the ventilation condition for individual apartments and offices
(Leung et al. 1998; Tso and Leung 1991; Tso et al. 1994). The 10-point system has no direct relevance with radon risk in those built-up areas in Hong Kong, which is in contrast to dwellings in some European countries. For instance, soil radon concentration and soil permeability are the two major factors in evaluating indoor radon risk in Germany. Yet, the 10-point radon potential system finds its usefulness in areas where people have to work underground, such as building tunnels, sewerage systems, etc. This work (Table 6) and some previous works (Tso and Leung 2000) revealed that the Ra-226 and Th-228 contents in Hong Kong granite are generally high, and hence careful planning of radon risk reduction is necessary for underground working environment, ground level and sub-ground level dwellings. 


\section{Conclusion}

A 10-point radon potential system was found to be correlated with soil radon concentration $\left(R^{2}=0.62-0.66\right)$, particularly in the places of relatively homogenous geology with medium value of radon potential. As Hong Kong stands on mostly high-uranium igneous rocks, the radon potential is quite significant and worthwhile for further studies. The 10-point system provides a cost-effective way to explore areas of unknown soil radon potential with mainly desk study of available geological maps. The system can be further applied more accurately and quickly through using aerial photography together with digital geological maps. Any varying environmental factor, e.g. faults and debris, over sediments and fracture zones may pose uncertainties to the system. For instance, radon concentration anomalies $\left(87.5-115.6 \mathrm{kBqm}^{-3}\right)$ were revealed along faults in Hong Kong (Table 8), which were about two times higher than the average radon concentration $\left(58.9 \mathrm{kBqm}^{-3}\right)$ in Hong Kong. This latter average is comparable to that of some European igneous areas, e.g. Eastern Czech Republic (average $51.4 \mathrm{kBqm}^{-3}$ ). In the future, the 10-point radon potential system should be further tested intensively near faults and along coastal areas to discover other possible controlling factors of soil radon potential.

Acknowledgments This research was partly supported by the Hong Kong Research Grant Council. Swire Institute of Marine Science (SWIMS) and Prof. Gray A. Williams provided great support to the experimental work in Cape D'aguilar. Gratitude is expressed to Prof. L. S. Chan and Dr. Jason Ali for their precious guidance and support to the field work. My special thanks are expressed to Robert Tong and Trudy Kwong for their helpful assistance in the fields, and Kawin Chan for GIS data analyses.

Open Access This article is distributed under the terms of the Creative Commons Attribution License which permits any use, distribution, and reproduction in any medium, provided the original author(s) and the source are credited.

\section{References}

Al-Tamimi MH, Abumurad KM (2001) Radon anomalies along faults in North of Jordan. Radiat Meas 34(1-6):397-400

Barnet I, Pacherova P, Neznal M, Neznal M (2008) Radon in geological environment-Czech experience. Czech Geological Survey Special papers 19

Bleile D, Wiegand J, Simopoulos ES (2005) Checking the "10 point system" for an evaluation of the soil radon potential. In: Radioactivity in the environment. Vol 7. Elsevier, Amsterdam, pp 833-841

Brookins DG (1990) The indoor radon problem. Columbia University Press, Columbia

Buttafuoco G, Tallarico A, Falcone G (2007) Mapping soil gas radon concentration: a comparative study of geostatistical methods. Environ Monit Assess 131(1-3):135-151
Chen T (1987) Basic features of the Lianhuashan Fault Zone in Hong Kong and Shenzhen area. J Guangdong Geol 2

Choubey VM, Bartarya SK, Ramola RC (2000) Radon in Himalayan springs: a geohydrological control. Environ Geol 39(6):523-530

Darby S, Hill D, Doll R (2001) Radon: a likely carcinogen at all exposures. Ann Oncol 12(10):1341-1351

Davis DW, Sewell RJ, Campbell SDG (1997) U-Pb dating of Mesozoic igneous rocks from Hong Kong. J Geol Soc London 154:1067-1076

Fufe JA, Shaw R, Campbell SDG, Lai KW, Kirk PA (2000) The quaternary geology of Hong Kong. Hong Kong Geological Survey: Government Publications Centre

Gadgil AJ (1992) Models of Radon Entry. Radiat Prot Dosim 45(1-4):373-380

Hagmaier JL (1972) Groundwater flow and uranium deposition, Powder River Basin, Wyoming. Am Assoc Petr Geol B 56(3):621

Harley NH, Fisenne LM, Harley JH, McGregor RG, Nero AV, Wilkening MH (1988) NRCP report no. 97: Measurement of radon and radon daughter in air

Huang T (1980) An outline of the tectonic characteristics of China. Continental Tectonics pp 184-197

Kemski J, Klingel R, Schneiders H, Siehl A, Wiegand J (1992) Geological structure and geochemistry controlling radon in soil gas. Radiat Prot Dosimetry 45(1-4):235-239

Kemski J, Klingel R, Siehl A (1996) Classification and mapping of radon-affected areas in Germany. Environ Int 22:S789-S798

Kemski J, Siehl A, Stegemann R, Valdivia-Manchego M (2001) Mapping the geogenic radon potential in Germany. Sci Total Environ 272(1-3):217-230

Kemski J, Klingel R, Siehl A, Valdivia-Manchego M (2009) From radon hazard to risk prediction-based on geological maps, soil gas and indoor measurements in Germany. Environ Geol 56(7):1269-1279

Kristiansson K, Malmqvist L (1982) Evidence for nondiffusive transport of Rn-86(222) in the ground and a new physical model for the transport. Geophysics 47(10):1444-1452

Leung J, Tso AYW, Ho C (1998) Behavior of 222Rn and its progeny in high-rise buildings. Health Phys 75(3):303

Lewis B, MacDonell M (1990) Release of radon-222 by vascular plants: effect of transpiration and leaf area. J Environ Qual 19(1):93-97

Reimer GM (1992) Using soil gas radon and geology to estimate regional radon potential. Radiat Prot Dosimetry 45(1-4):219-221

Sewell RJ (1999) Geochemical Atlas of Hong Kong. Hong Kong Geological Survey: Government Publications Centre

Sewell R, Campbell SDG, Fletcjer CJN, Lai KW, Kirk PA (2000) The pre-quaternary geology of Hong Kong. Hong Kong Geological Survey: Government Publications Centre

Tso MW, Leung JKC (1991) Survey of indoor 222 Rn concentrations in Hong Kong. Health Phys 60(2):237

Tso M, Leung J (2000) Population dose due to natural radiation in Hong Kong. Health Phys 78(5):555

Tso MYW, Ng CY, Leung JKC (1994) Radon release from building materials in Hong Kong. Health Phys 67(4):378

UNSCEAR (1994) Unscear 1993. Nucl Energ-J Br Nucl 33(3):132-133

Wiegand $J$ (2001) A guideline for the evaluation of the soil radon potential based on geogenic and anthropogenic parameters. Environ Geol 40(8):949-963

Wiegand J (2005) A semi quantitative method to evaluate the soil radon potential: The "10 Point System". Zeitschrift des Lehrund Forschungsbereichs Hydrogeologie und Umwelt Heft 33(1):1-10 (available from http://hydrogeologie-wuerzburg.de/ HU33_pdfs/HU33_11_Wiegand_Radon.pdf)

Yu K, Young E, Li K (1996) A survey of radon properties for dwellings for Hong Kong. Radiat Prot Dosimetry 63(1):55 